Corresponding Author: Mohammed Alhassan, MD; +966505198904

email:

mhmdarhafeez@yahoo.com

Received 26 April 2020

Accepted 18 June 2020

Published 30 June 2020

Production and Hosting by Knowledge E

(c) Mohammed Alhassan, MD. This article is distributed under the terms of the Creative Commons

Attribution License, which permits unrestricted use and redistribution provided that the original author and source are credited.

Editor-in-Chief:

Prof. Mohammad A. M. Ibnouf
Research Article

\section{Assessment of Dehydration in Children with Acute Gastroenteritis: A Narrative Review of International Guidelines}

\section{Mohammed Alhassan, MD}

Department of Pediatric, College of Medicine, Prince Sattam Bin Abdulaziz University, Alkharj 11942, Saudi Arabia

\section{Abstract}

Background: Acute Gastroenteritis (AGE) is a major cause of presentation to hospital in children. Detection and classification of the degree of dehydration are vital for proper treatment.

Methods: The authors reviewed six international guidelines on AGE in children. The aim was to equip clinicians working in a hospital setting with practical and readily applicable clinical handles to assist them in detecting and classifying dehydration.

Results: Published international guidelines on AGE vary in their recommendations on the assessment of dehydration as well as their classification of dehydration severity. Nevertheless, a practical scheme utilizing a combination of these guidelines could be devised.

Conclusion: In addition to the World Health Organization classification of dehydration in children, several clinical handles were suggested.

Keywords: acute gastroenteritis, children, dehydration, diarrhea

\section{Introduction}

Acutegastroenteritis ( $A G E$ ) and its complications remain one of the leading causes of mortality in children worldwide [1]. In underdeveloped countries, the disease poses a particular burden on the resource-limited healthcare systems; enormously higher mortality rates from the disease in sub-Saharan Africa, for example, is not unexpected [2]. In some regions of Africa, diarrheal diseases remain the leading cause of hospital presentation and the second most common cause of death in children under five years of age (excluding the neonatal period) [3]. In places with underdeveloped, underresourced, and overburdened community and primary care services, a considerable percentage of patients with AGE present to the emergency departments (EDs) of large hospitals without passing through primary healthcare services. This necessitates an easy and reliable tactic to quickly and efficiently detect and classify dehydration in 
working in a hospital setting with practical and readily applicable clinical handles to assist them in detecting and classifying dehydration. The article may be useful mainly for physicians working at moderately to markedly under-resourced pediatric EDs.

Clinical practice guidelines have been defined as "statements that include recommendations intended to optimize patient care, and that are informed by a systematic review of evidence and an assessment of the benefits and harms of alternative care options" [4]. It has been demonstrated that adherence to robust clinical practice recommendations and guidelines improves the outcomes, lowers the rate of hospital admissions, reduces the duration of hospital stay, and lowers the financial costs attributable to diarrheal diseases in children [5,6]. However, when individual guidelines cannot provide satisfactory answers to all practice ambiguities across all settings, poor adherence to these guidelines is an expected outcome [7]. Inconsistencies in recommendations among different guidelines further complicate things for practicing physicians.

Classifying dehydration into subgroups is an "essential basis" for appropriate rehydration [8]. This review of the international guidelines aims at providing practical answers to the following clinical questions relevant to the management of $A G E$ in children.

-What is the utility of individual clinical signs and symptoms in detecting and categorizing dehydration?

-What is the most convenient and practical way of classifying the degree of dehydration in an ED?

This has been done after reviewing, utilizing, and combining practical recommendations from international guidelines, taking into consideration the peculiarities of the organization of services, processes, and setting of a typical resource-limited yet busy hospital's ED.

\section{Materials and Methods}

\subsection{Selecting, retrieving, and reviewing the guidelines}

In addition to the existing World Health Organization (WHO) guidelines for treating diarrhea in children, five international guideline documents addressing acute diarrhea/gastroenteritis and dehydration were retrieved from the websites of the relevant professional organizations and institutions. The guidelines are:

- The WHO guidelines on the treatment of diarrhea in children [9-11].

- National Institute for Health and Care Excellence (NICE) guidelines [12, 13]. 
- Cincinnati Children's Hospital (CCH) Medical Center's guidelines on AGE In children aged 2 months through 5 years [14].

- Guidelines for the management of acute gastroenteritis in children in Europe (ESP) [15].

- Canadian Pediatric Society (CPS) position statement on "Oral rehydration therapy and early refeeding in the management of childhood gastroenteritis" [16].

- "Managing Acute Gastroenteritis Among Children" from the Centers for Disease Control and Prevention (CDC) [17].

These guidelines were chosen based on their international reputability in addition to their quality being critically appraised previously by Van Den Berg and Berger [18]. No further critical appraisal of data has been done in this article.

The author initially formulated the clinical practice questions mentioned previously (in the Introduction section). Each guideline document was then thoroughly reviewed with a focus on fetching recommendations that answer the research questions. These recommendations were first assessed on whether they were based on evidence of an acceptable level or were graded as strong recommendations. This was partly based on the information extracted from [18] in addition to the guidelines themselves where available. Next, a decision about each recommendation applicability to the practice area of concern (i.e., a large hospital ED) was made based on the author's judgment and experience in working in the same setting for around six years in Sudan. Finally, practical conclusions were suggested building on one or more corresponding recommendations from the international guidelines.

\subsection{Target patients}

AGE has been defined as a diarrheal disease of acute onset "with or without accompanying nausea, vomiting, fever, or abdominal pain" [14]. Diarrhea is the passage of unusually loose or liquid stool, typically $\geq 3$ times per 24 hr. However, "a change in stool consistency versus previous stool consistency" is more indicative of diarrhea than the frequency of defecation $[9,15]$.

This review is intended primarily for use in children aged one week to five years with clinically confirmed AGE. It is important to note that the review does not apply to the following categories:

- AGE in a severely malnourished child (see the WHO definition of severe acute malnutrition [19]. 
- Acute diarrhea with or without vomiting as a result of non-gastrointestinal illness, for example, sepsis, urinary tract infection, and meningitis.

- Iso-, hypo-, or hypernatremic dehydration resulting from causes other than AGE, for example, acute adrenal crisis and vomiting with no diarrhea.

\subsection{Audience}

This review will be helpful primarily to practicing pediatricians, pediatric, and pediatric emergency medicine (PEM) trainees working in an ED setting. Although it is more directed to a resource-limited hospital, clinicians in all ranges of EDs may find it useful.

\section{Results and Discussion}

Almost all reviewed guidelines agreed on using a three-category classification of no $<<$ $5 \%$ ) dehydration, some (mild to moderate) (5 to $9 \%$ ) dehydration, and severe ( $\geq 10 \%)$ dehydration (the quoted percentages of loss are the ones used by the WHO). The fourcategory classification has mostly been avoided [20] because of poor interobserver reliability. The guidelines, however, vary in the use of clinical symptoms and signs to assess dehydration. Measuring the child's weight and comparing it to a recent measurement to calculate the percentage fluid loss was not used by any guideline to classify dehydration because of impracticality and accuracy issues.

The WHO and NICE guidelines emphasized on hypovolemic shock as a clinical entity with a greater percentage of body fluid loss and higher fluid requirement than "severe dehydration" [11, 21]. Both guidelines stressed the crucial importance of early recognition and emergency treatment of hypovolemic shock. The WHO characterizes shock diagnosis as based on the clinical signs of cold hands, prolonged capillary refill time of $>3 \mathrm{sec}$, and weak pulses on top of signs of severe dehydration. NICE guidelines pointed out that a child with shock might have a more profound depressed level of consciousness and more pronounced tachycardia than dehydration. They restated that the manifestations of advanced shock would be unequivocal, however, milder degrees of shock might be challenging to distinguish from severe dehydration, concluding that "when there was uncertainty, the safe approach would be to treat as though shock was present." Importantly also, NICE suggested that, in some cases, when an infant develops rapid fluid losses, shock may ensue before the signs of severe dehydration (e.g., slow skin pinch and dry tongue) are manifested. Other guidelines did not define 
the "shock" category. Hypotension was agreed on to be a late sign of severe shock. The presence of normal blood pressure does not rule out shock [22].

Some individual signs have increased the likelihood in detecting $\geq 5 \%$ dehydration, that is, "some dehydration" and worse. The best "individual" signs to indicate dehydration were abnormal skin turgor, absent tears, abnormal (deep/rapid/acidotic) respiratory pattern, and prolonged capillary refill (ESP, CCH, and NICE citing the study of Steiner et al. [23]). These were the highest in specificity (and likelihood ratio (LR)) for detecting $\geq 5 \%$ (some or severe) dehydration. This means that the finding of any one of these signs is likely indicative that the child is dehydrated, but without taking the degree of dehydration into account (see page 9 in [14] and Table 4.1 in [18]). An altered mental status of any degree (irritability, restlessness, lethargy, coma), sunken eyes, and dry mucus membranes (except for mouth breather) were also consistent individual signs of dehydration across all guidelines, except the WHO that did not assess for mucus membranes. However, their individual LRs for detecting dehydration were less than those for the signs mentioned previously [23]. Poor general appearance, dry mucous membranes, and sunken eyes also had the highest individual sensitivity for detecting $\geq$ $5 \%$ dehydration [21]. More importantly, the absence of these signs individually had the lowest LR (negative LR $=0.46,0.41,0.49$, respectively [23]). This implies that children with AGE are likely not dehydrated if they appear well, do not have sunken eyes, or have moist mucous membranes (when no recent drinking).

Tachycardia, although a consistently mentioned sign of dehydration in all reviewed guidelines, may also occur in a well-hydrated child with coexisting fever, abdominal pain, or anxiety [24]. This markedly lowers its utility in detecting dehydration (positive LR of 1.3 [23]). However, this consistency in guidelines might make the absence of tachycardia a reasonable indicator that a child is not severely dehydrated. The heart rate in some children with no or some dehydration may be normal (CDC, CPS, CCH, NICE). $\mathrm{CCH}$ and CDC guidelines also drew attention to the fact that bradycardia can occur in the most severe cases (of dehydration or shock).

Assessment of tears was not part of the evaluation of dehydration in three out of six guidelines (WHO, CPS, NICE). However, the presence of normal tears would argue against severe $(\geq 10 \%)$ dehydration. Assessment of the anterior fontanelle was used only by $\mathrm{CCH}$ and $\mathrm{CPS}$ guidelines, and its use was deemed "unreliable and misleading" by the CDC. Parental reports of symptoms/signs of dehydration were not part of the assessment in all but one (NICE) guidelines. Parental reporting was stated as being not clinically useful by ESP guidelines. The latter, however, strongly recommends that "parental report of normal urine output decreases the likelihood of dehydration" [15]. 
At the same time, NICE guidelines stated that "some reassurance could be taken if the urine output was said to be normal" [13] (see Table 1).

TABLE 1: Assessment and classification of dehydration. ${ }^{A}$

\begin{tabular}{|c|c|c|c|c|c|}
\hline Parameter & $\begin{array}{l}\text { No dehy- } \\
\text { dration } \\
(<5 \%)\end{array}$ & $\begin{array}{l}\text { Some } \\
\text { dehydra- } \\
\text { tion } \\
(5-9 \%)^{B}\end{array}$ & $\begin{array}{l}\text { Severe } \\
\text { dehydration } \\
(\geq 10 \%)^{B}\end{array}$ & $\begin{array}{l}\text { Hypovolemic } \\
\text { shock } \\
(>>10 \%)\end{array}$ & Comment \\
\hline $\begin{array}{l}\text { Mental status } \\
\text { and general } \\
\text { condition }\end{array}$ & $\begin{array}{l}\text { Well, } \\
\text { alert }^{C}\end{array}$ & $\begin{array}{l}\text { Restless, } \\
\text { irritable }\end{array}$ & $\begin{array}{l}\text { Lethargic or } \\
\text { unconscious }^{D}\end{array}$ & $\begin{array}{l}\text { Lethargic or } \\
\text { unconscious }{ }^{D}\end{array}$ & $\begin{array}{l}\text { A well-appearing alert child } \\
\text { decreases the likelihood of } \\
\text { dehydration. (Sensitivity of } \\
\text { abnormal general appearance }= \\
0.80)^{E}\end{array}$ \\
\hline Eyes & Normal $^{C}$ & $\begin{array}{l}\text { Sunken } \\
\text { eyes** }\end{array}$ & $\begin{array}{l}\text { Sunken } \\
\text { eyes** }\end{array}$ & $\begin{array}{l}\text { Sunken } \\
\text { eyes** }\end{array}$ & $\begin{array}{l}\text { Normal eye (not sunken) } \\
\text { decreases the likelihood of } \\
\text { dehydration. (Sensitivity of } \\
\text { sunken eyes }=0.75)^{E}\end{array}$ \\
\hline Skin pinch & $\begin{array}{c}\text { Goes back } \\
\text { quickly }\end{array}$ & $\begin{array}{l}\text { Goes back } \\
\text { slowly } F\end{array}$ & $\begin{array}{l}\text { Goes back } \\
\text { very slowly } \\
(\geq 2 \mathrm{sec})^{F}\end{array}$ & $\begin{array}{l}\text { Goes back } \\
\text { very slowly } \\
(\geq 2 \text { sec })^{F}\end{array}$ & $\begin{array}{l}\text { Abnormal skin pinch alone } \\
\text { increases the likelihood of } \geq 5 \% \\
\text { dehydration (not in the severely } \\
\text { malnourished child) }\end{array}$ \\
\hline Thirst & $\begin{array}{l}\text { Drinks } \\
\text { normally, } \\
\text { no } \\
\text { excessive } \\
\text { thirst }\end{array}$ & $\begin{array}{l}\text { Thirsty, } \\
\text { drinks } \\
\text { eagerly }\end{array}$ & $\begin{array}{l}\text { Drinks poorly } \\
\text { or is unable } \\
\text { to drink }\end{array}$ & $\begin{array}{l}\text { Drinks poorly } \\
\text { or is unable } \\
\text { to drink }\end{array}$ & \\
\hline Hands/extremi & $-{ }^{G}$ & - & - & $\begin{array}{l}\text { Cold } \pm \text { pale } \\
\text { and mottled }\end{array}$ & $\begin{array}{l}\text { If hands are warm, the child } \\
\text { probably does not have } \\
\text { hypovolemic shock (distributive } \\
\text { types of shock may cause warm } \\
\text { hands). }\end{array}$ \\
\hline
\end{tabular}

Breathing $^{F} \quad$ Acidotic breathing alone in the context of AGE increases the likelihood of $>>5 \%$ dehydration. ${ }^{H}$

Capillary refill time (CRT)
Delayed $>3$ $\sec ^{F}$
A delayed CRT alone in the context of $A G E$ increases the likelihood of $>>5 \%$ dehydration. 


\begin{tabular}{|c|c|c|c|c|c|}
\hline Parameter & $\begin{array}{l}\text { No dehy- } \\
\text { dration } \\
(<5 \%)\end{array}$ & $\begin{array}{c}\text { Some } \\
\text { dehydra- } \\
\text { tion } \\
(5-9 \%)^{B}\end{array}$ & $\begin{array}{c}\text { Severe } \\
\text { dehydration } \\
(\geq 10 \%)^{B}\end{array}$ & $\begin{array}{l}\text { Hypovolemic } \\
\text { shock } \\
(>>10 \%)\end{array}$ & Comment \\
\hline Pulse rate & - & - & - & $\begin{array}{l}\text { Increased } \\
\text { (decreased in } \\
\text { most severe } \\
\text { cases) }\end{array}$ & $\begin{array}{l}\text { Poor discriminatory sign for } \\
\text { dehydration as coexisting fever, } \\
\text { pain, anxiety may also cause } \\
\text { tachycardia. A normal pulse rate } \\
\text { decreases the likelihood of } \\
\text { severe dehydration. }\end{array}$ \\
\hline Pulse volume & - & - & - & Weak & $\begin{array}{l}\text { If the pulse is strong and not } \\
\text { fast, the child is not in shock [11]. }\end{array}$ \\
\hline $\begin{array}{l}\text { Mucous } \\
\text { membranes }\end{array}$ & $\begin{array}{l}\text { Moist (not } \\
\text { after a } \\
\text { drink) }\end{array}$ & - & - & - & $\begin{array}{l}\text { Moist tongue decreases the } \\
\text { likelihood of } \geq 5 \% \text { dehydration. } \\
\text { (Sensitivity of dry mucous memb. } \\
=0.86)^{E}\end{array}$ \\
\hline Tears & Normal & - & Absent $^{F}$ & Absent & $\begin{array}{l}\text { Absent tears alone increases the } \\
\text { likelihood of } \geq 5 \% \text { dehydration } \\
\text { (not in severely malnourished } \\
\text { children). Normal tears } \\
\text { decreases the likelihood of } \\
\text { severe dehydration. (Sensitivity } \\
\text { of absent tears }=0.63)^{E}\end{array}$ \\
\hline
\end{tabular}

${ }^{A}$ This table is a modification and expansion of the WHO classification of dehydration in children. The shaded cells represent the WHO classification of dehydration. Use these first to classify dehydration. If in doubt, supplement clinical judgment by using unshaded cells.

${ }^{B}$ Two or more signs classify children in this category.

${ }^{C}$ Any one negative (normal) sign makes $\geq 5 \%$ dehydration unlikely.

${ }^{D}$ Lethargy here means dull mental status, and the child cannot be fully awakened.

${ }^{E}$ Data from [23].

${ }^{F}$ Any one positive sign indicates a high likelihood of $\geq 5 \%$ dehydration.

${ }^{G}$ A dash (-) means the presence or absence of the sign is not very useful in detecting or classifying this category of dehydration.

${ }^{H}$ Acidotic $=$ deep \pm rapid breathing

**"In some infants and children, the eyes normally appear somewhat sunken. It is helpful to ask the mother if the child's eyes are normal or more sunken than usual." [9]

\subsection{Practice bottom line}

- It is recommended to use the WHO guidelines for the assessment and classification of dehydration in a pediatric ED setting, particularly a resource-limited one.

- Hypovolemic shock represents a higher fluid deficit than severe dehydration.

- Hypovolemic shock should be strongly considered if a child has features of severe dehydration and, in addition, has decreased level of consciousness, cold hands, prolonged capillary refill time, and weak and markedly fast pulses.

- If the pulse is strong and not fats, the child is not in shock.

- If in doubt, the child should be treated as if shock was present. 
- In addition to the WHO classification of dehydration, the following general guides may provide clinical handles to supplement the assessment process and remove potential uncertainty.

- The presence of any one of the following signs increases the likelihood of at least some $(\geq 5 \%)$ dehydration (note that these signs do not indicate the degree of dehydration [some versus severe] when used individually).

* Prolonged capillary refill time

* Slow return of skin pinch (except in severe malnutrition)

* Acidotic (deep \pm rapid) breathing

* Absent tears (except in severe malnutrition)

- A child with any one of the following signs is likely not dehydrated.

* Well appearing and alert

* Eyes not sunken

* Moist mucus membranes (except after a drink)

- A child with any one of the following signs is likely not severely dehydrated.

* Normal tears

* Normal pulse rate (bradycardia can occur in most severe cases of shock)

- The examination of anterior fontanel is not reliable in the assessment of dehydration.

- Parental reporting of normal urine output decreases the likelihood of $\geq 5 \%$ dehydration.

\section{Conclusion}

The WHO classification of dehydration in children with AGE seems simple yet practical. With a supplement of clinical handles from other international guidelines, as suggested in this article, a clinician may find himself better equipped for a more accurate and quicker clinical assessment in a busy hospital ED setting.

\section{Conflict of Interest}

The author declares that there is no conflict of interest. 


\section{References}

[1] Troeger, C., Blacker, B. F., Khalil, I. A., et al. (2018). Estimates of the global, regional, and national morbidity, mortality, and aetiologies of diarrhoea in 195 countries: a systematic analysis for the Global Burden of Disease Study 2016. The Lancet Infectious Diseases, vol. 18, no. 11, pp. 1211-1228. Retreived from: http://dx.doi.org/10.1016/ [accessed March 19, 2020].

[2] Boschi-Pinto, C., Lanata, C. F., Mendoza, W., et al. (2006). Diarrheal diseases. In Disease and Mortality in Sub-Saharan Africa ( $2^{\text {nd }}$ ed.). Washington (DC): The International Bank for Reconstruction and Development/The World Bank. Retreived from: http://www.ncbi.nlm.nih.gov/pubmed/21290663 [accessed Mar 26, 2020].

[3] Wold Health Organisation. (2015). WHO EMRO I Sudan I Data and statistics I Child and Adolescent Health. Retreived from: http://www.emro.who.int/child-adolescenthealth/data-statistics/sudan.html [accessed Mar 20, 2020].

[4] American Academy of Family Physicians. (2018). Clinical Practice Guideline Manual - Clinical Recommendation. Retreived from: https://www.aafp.org/patient-care/ clinical-recommendations/cpg-manual.html [accessed Mar 19, 2020].

[5] Perlstein, P. H., Lichtenstein, P., Cohen, M. B., et al. (2002). Implementing an evidencebased acute gastroenteritis guideline at a children's hospital. The Joint Commission Journal on Quality Improvement, vol. 28, no. 1, pp. 20-30.

[6] Zolotor, A. J., Randolph, G. D., Johnson, J. K., et al. (2007). Effectiveness of a practice-based, multimodal quality improvement intervention for gastroenteritis within a medicaid managed care network. Pediatrics, vol. 120, no. 3, pp. e644-e650. Retreived from: http://www.ncbi.nlm.nih.gov/pubmed/17766504 [accessed Mar 19, 2020].

[7] Salih, K. E. M., Bilal, J. A., Alfadeel, M. A., et al. (2014). Poor adherence to the world health organization guidelines of treatment of severe pneumonia in children at Khartoum, Sudan. BMC Research Notes, vol. 7, no. 1, pp. 1-4.

[8] Guarino, A., Ashkenazi, S., Gendrel, D., et al. (2014). European Society for Pediatric Gastroenterology, Hepatology, and Nutrition/European Society for Pediatric Infectious Diseases evidence-based guidelines for the management of acute gastroenteritis in children in Europe: update 2014. Journal of Pediatric Gastroenterology Nutrition, vol. 59, pp. 132-152.

[9] WHO. (2005). The Treatment of Diarrhoea: A Manual for Physicians and Other Senior Health Workers. Retreived from: http://scholar.google.com/scholar?hl= en\&btnG=Search\&q=intitle:THE+TREATMENT+OF+DIARRHOEA+A+manual+for+ 
physicians+and+other+senior+health+workers\#0\{\%\}5Cnhttp://scholar.google.com/ scholar?hl=en\&btnG=Search\&q=intitle:The+treatment+of+diarrhoea:+a+manual+for+ ph [accessed Mar 19, 2020].

[10] WHO. (2010). Existing WHO Guidelines for Preventing and Treating Diarrhoea in Children. Retreived from: https://www.ncbi.nlm.nih.gov/books/NBK305340/ [accessed Mar 19, 2020].

[11] WHO. (2013). Hospital Care For Children (2nd ed.), p. 17. Geneva: WHO. Retreived from: www.who.int/maternal_child_adolescent/en [accessed March 22, 2020].

[12] National Collaborating Centre for Women's and Children's Health (UK). (2009). Diarrhoea and Vomiting Caused by Gastroenteritis. NICE Clinical Guidelines, pp. 7-10. Retreived from: http://www.ncbi.nlm.nih.gov/books/NBK63844/

[13] National Collaborating Centre for Women's and Children's Health. (2009). Diarrhoea and Vomiting Caused by Gastroenteritis: Diagnosis, Assessment and Management in Children Younger than 5 Years, p. 44. London, UK: RCOG Press. Retreived from: http://www.ncbi.nlm.nih.gov/books/NBK63844/ [accessed March 19, 2020].

[14] Cincinnati Children's Hospital Medical Center. (2011). Evidence-based care guideline: prevent and management of acute gastroenteritis (AGE) in children aged 2 months to 18 years. Retreived from: http://www.cincinnatichildrens.org/WorkArea/ DownloadAsset.aspx?id=93672 [accessed March 19, 2020].

[15] Guarino, A., Ashkenazi, S., Gendrel, D., et al. (2014). European society for pediatric gastroenterology, hepatology, and nutrition/european society for pediatric infectious diseases evidence-based guidelines for the management of acute gastroenteritis in children in Europe: Update 2014. Journal of Pediatric Gastroenterology and Nutrition, vol. 59, no. 1, pp. 132-152. Retreived from: www.jpgn.org [accessed March 19, 2020].

[16] Leung, A. K. C. and Barankin, B. (2006). Oral rehydration therapy and early refeeding in the management of childhood gastroenteritis. Paediatrics and Child Health, vol. 11, no. 8, pp. 527-531.

[17] King, C. K., Glass, R., Bresee, J. S., et al. (2003). Managing acute gastroenteritis among children: oral rehydration, maintenance, and nutritional therapy. MMWR Recommendations and Reports, vol. 52, no. RR-16, pp. 1-16.

[18] Van Den Berg, J. and Berger, M. Y. (2011). Guidelines on acute gastroenteritis in children: a critical appraisal of their quality and applicability in primary care. $B M C$ Family Practice, vol. 12, p. 134. Retreived from: http://www.biomedcentral.com/14712296/12/134 [accessed March 14, 2020]. 
[19] WHO. (2009). Severe Acute Malnutrition. WHO. Retreived from: https://www.who. int/nutrition/topics/malnutrition/en/ [accessed March 26, 2020].

[20] Nazarian, L. F., Berman, J. H., Brown, G., et al. (1996). Practice parameter: the management of acute gastroenteritis in young children. Pediatrics, vol. 97, pp. 424-436.

[21] National Collaborating Centre for Women's and Children's Health. (2009). Assessing Dehydration and Shock. London, UK: RCOG Press. Retreived from: https://www.nice.org.uk/guidance/cg84/documents/cg84-diarrhoea-and-vomitingin-children-under-5-evidence-tables2 [accessed March 23, 2020].

[22] Advanced Medical Certification. Diagnosing Shock - PALS Online Handbook. Retreived from: https://advancedmedicalcertification.com/lesson/diagnosing-shockpals-online-handbook/ [accessed March 22, 2020].

[23] Steiner, M. J. and Dewalt, D. (2004). Is this child dehydrated? Clinical Scenarios: JAMA, vol. 291, no. 22. pp. 2746-2754.

[24] Fleming, S., Thompson, M., Stevens, R., et al. (2011). Normal ranges of heart rate and respiratory rate in children from birth to 18 years of age: A systematic review of observational studies. Lance, vol. 377, no. 9770, pp. 1011-1018. 